\title{
Qualidade higiênico - sanitária da carne de hambúrguer Industrializada
}

\author{
Lívia Freitas de MELO ${ }^{1 *}$ \\ Natália de Almeida VILELA ${ }^{2}$ \\ Patrícia Lunardelli Negreiros de CARVALHO ${ }^{5}$ \\ Sandra Maria Oliveira Morais VEIGA ${ }^{4}$ \\ Luiz Carlos do NASCIMENTO ${ }^{3}$
}

\begin{abstract}
${ }^{1,2}$ Graduanda em Farmácia. Departamento de Alimentos e Medicamentos - Faculdade de Ciências Farmacêuticas, Universidade Federal de Alfenas (UNIFAL-MG).

${ }^{3}$ Doutor, Professor de Microbiologia de Alimentos e Saúde Coletiva. UNIFAL-MG E-mail: luizcnascimento@gmail.com

${ }^{4}$ Doutora, Professora de Saúde Coletiva aplicada à Farmácia, Controle de Qualidade Microbiológica de Alimentos e Microbiologia de Alimentos. UNIFAL-MG. E-mail: smveiga@gmail.com

${ }^{5}$ Mestre em Ciências Farmacêuticas. Departamento de Alimentos e Medicamentos - Faculdade de Ciências Farmacêuticas, Universidade Federal de Alfenas. E-mail: patrikapnc@gmail.com

*liviafmelo@yahoo.com.br
\end{abstract}

Recebido em: 30/10/2012 - Aprovado em: 28/12/2012 - Disponibilizado em: 30/12/2012

RESUMO: O interesse por produtos alimentícios nutritivos, baratos e de fácil preparo tornou a carne de hambúrguer um dos alimentos de crescente consumo no Brasil. Entretanto, as carnes e seus derivados constituem veículo potencial de contaminantes, contribuindo para a instalação e proliferação de patógenos nas diversas fases de seu processamento, sendo responsável por diversas patologias. Desta forma, é necessário, durante a obtenção da carne de hambúrguer, assegurar a qualidade higiênico-sanitária estabelecida pelas diretrizes da RDC nº12/2001 (ANVISA) para prevenir ou minimizar o número de doenças veiculadas por estes alimentos. Portanto, o presente trabalho teve como objetivo avaliar as características microbiológicas da carne de hambúrguer bovina, por meio da detecção de coliformes (em especial a Escherichia coli), Salmonella sp, Staphylococcus aureus, psicrotróficos, aeróbios mesófilos, fungos filamentosos e Clostrídios sulfito redutores, ressaltando a importância da conscientização dos consumidores desse tipo de carne. Após análise de todas as marcas de hambúrguer, verificou-se que $80 \%$ encontra-se de acordo com a legislação vigente; entretanto três amostras apresentaram alta contagem para aeróbios mesófilos e psicrotróficos. A divulgação dos resultados poderia alertar os consumidores e os produtores, evitando, assim, as toxinfecções alimentares e suas complicações, além de fornecer subsídios para atuação mais eficaz da Vigilância Sanitária e órgãos competentes, contribuindo para a obtenção de um produto seguro e saudável.

Palavras-chave: Hambúrgueres. Higiene dos Alimentos. Microbiologia dos Alimentos. Agência Nacional de Vigilância Sanitária. DTA.

\begin{abstract}
Interest in food nutritious products, inexpensive and easy to prepare made the beef burger one of the growing food consumption in Brazil. However, the meat and its derivatives are potential vehicle of contamination, contributing to the installation and proliferation of pathogens at many stages of processing, being responsible for several pathologies. Thus, it is necessary for obtaining the hamburger meat, to ensure the sanitary quality guidelines established by the RDC No. 12/2001 (ANVISA) to prevent or minimize the number of these diseases caused by contaminated food. Therefore, this study aims to evaluate the microbiological characteristics of beef hamburger meat, through the detection of coliforms (especially Escherichia coli), Salmonella, Staphylococcus aureus, psychrotrophic, mesophilic aerobic, filamentous fungi, Clostridium sulfite reducer and highlighting the importance of consumer awareness of this type of meat. After reviewing all brands of hamburger, it was found $80 \%$ is in accordance with current legislation, however three samples showed high counts for mesophilic aerobic and psychrotrophic. The dissemination of results could alert consumers and producers, thus avoiding the food poisoning and its complications and even provide support for more effective action of the Sanitary Vigilance and competente organs, contributing to the achievement of a safe and healthy product.
\end{abstract}

Keywords: Hamburgers. Food Hygiene. Food Microbiology. National Agency for Sanitary Vigilance. DTA. 


\section{Introdução}

O hambúrguer é um produto cárneo industrializado submetido a um processo de manipulação que pode influenciar no seu sistema de conservação, favorecendo a instalação e a veiculação de microorganismos (ALMEIDA, 2004).

Considerando-se tais características, tornam-se necessárias a avaliação microbiológica e a adoção de práticas adequadas para sua conservação e preparação, a fim de garantir que o consumo ocorra de forma segura e livre de contaminação (ALMEIDA, 2004), evitando-se as enfermidades transmitidas por alimentos (ETAs).

A qualidade da carne destinada ao consumo é motivo de constante preocupação em todo o mundo, em especial no Brasil, país considerado o segundo maior produtor de carne bovina do mundo e que vêm mantendose como maior exportador (ABIEC, 2011).

Assim, no Brasil a resolução RDC $\mathrm{n}^{\circ} 12 / 2001$ da Anvisa (BRASIL, 2001) estabelece parâmetros que regulamentem a produção e manipulação desses produtos para garantir a segurança do alimento, de forma a assegurar a fiscalização de parâmetros intrínsecos e extrínsecos que permitam preservar a microbiota natural da carne e ainda evitar a instalação e proliferação de patógenos.

A contaminação de hambúrguer bovino está relacionada a surtos de colites hemorrágicas causadas por Escherichia coli 0157:H7, de gastroenterites por Salmonella sp, e tem contribuído por elevar consideravelmente a frequência de toxinfecções alimentares em nível mundial (TAVARES, 2002).

Assim, objetivou-se verificar se a qualidade de amostras de hambúrgueres industrializados está condizente com a RDC $\mathrm{n}^{\mathrm{o}}$ 12/2001 (BRASIL, 2001), realizando para isso, a pesquisa de micro-organismos indicadores, além de outros capazes de comprovar as condições higiênico-sanitárias na obtenção destes produtos.

\section{Material e Método}

Processaram-se um total de 15 amostras de carne de hambúrgueres industrializados. Foram analisadas cinco marcas diferentes de carne de hambúrguer industrializado, denominadas nesse trabalho como “A", "B", “C”, "D" e "E", respectivamente.

Para cada marca avaliada, foram retiradas três amostras do mesmo lote e as análises aconteceram em triplicata.

Os ensaios microbiológicos consistiram na pesquisa de Escherichia coli e Salmonella sp, quantificação de coliformes, estafilococos coagulase positivo, psicrotróficos, aeróbios mesófilos, fungos filamentosos e Clostridium sulfito redutores, conforme recomendações da RDC 12/2001 e metodologia descrita por Silva et al. (2007). 
Os parâmetros microbiológicos e sanitários adotados foram de acordo com o Regulamento Técnico sobre os Padrões Microbiológicos para Alimentos do Ministério da Saúde (RDC ANVISA $n^{\circ} 12 / 2001$ ), que preconiza a ausência de Salmonella sp em carnes resfriadas, ou congeladas, "in natura", de bovinos, suínos e outros mamíferos.

\section{Resultados e Discussão}

Em todas as marcas de hambúrguer analisadas neste trabalho, não foi detectada a presença de Salmonella $s p$, da mesma forma que Marchi (2006) em sua pesquisa com carne moída.

Segundo o FDA (2005a) e Jay (2005), concentrações em torno de $10^{7}$ a $10^{9}$ células/g de alimentos são necessárias para que ocorra uma salmonelose, embora a ingestão de alimentos com pelo menos 15 a 20 células possa causar infecção, dependendo da idade e da imunidade do indivíduo.

Outros indicadores microbiológicos avaliados neste trabalho apresentaram perfis e quantificações diferentes entre as marcas conforme apresentado na Tabela 1.

Os micro-organismos fungos filamentosos e leveduras, aeróbios mesófilos e psicrotróficos são deteriorantes, no entanto, sua pesquisa não é exigida pela legislação.

As marcas apresentaram baixa quantificação de fungos filamentosos $\mathrm{e}$ leveduras. A marca "A" apresentou uma quantificação média de 0,6 x10 UFC/g; a marca "B": 1x10 UFC/g; a marca "C": 1,2 x 10 UFC/g; marca "D": 6x10 UFC/g e a marca "E": 2x10 UFC/g.

Lundgren et al. (2009), ao avaliar a qualidade da carne bovina comercializada em feiras livres realizou a determinação de bolores e leveduras encontrando um valor médio de $2,7 \times 10^{5} \mathrm{UFC} / \mathrm{g}$.

Cabe salientar que a legislação brasileira não estabelece limites para bolores e leveduras em carne moída. Entretanto, esse grupo de micro-organismos pode produzir micotoxinas, além de agir acelerando a deterioração dos alimentos, sendo que sua alta contagem torna-se indicativa de precárias condições de operações no processamento de alimentos (MARCHI, 2006).

Para os micro-organismos aeróbios mesófilos a contagem mostrou-se alta sendo que a marca "A" apresentou média de 2,5 $\mathrm{x} 10^{5} \mathrm{UFC} / \mathrm{g}$; a marca "B": $2,1 \times 10^{5} \mathrm{UFC} / \mathrm{g}$; marca "C": $2,3 \times 10^{8} \mathrm{UFC} / \mathrm{g}$; marca "D": 1,5 x $10^{5} \mathrm{UFC} / \mathrm{g}$ e a marca "E": 5,3 x107 UFC/g.

Segundo Tavares (2002) os microorganismos encontrados com maior freqüência foram os aeróbios mesófilos. De acordo com o Centro Nacional de Alimentacioón y Nutrición de Majadahonda o valor máximo permitido é $10^{5} \mathrm{UFC} / \mathrm{g}$ para produtos cárneos prontos para o consumo. Lundgren et al. (2009), observou que o valor médio do número de bactérias aeróbias mesófilas foi $3,0 \times 10^{7} \mathrm{UFC} / \mathrm{g}$, demonstrando 
uma contagem consideravelmente alta, tal como das marcas "C" e "E".

Os valores médios encontrados para psicrotróficos foram, marca "A": 7,2×10 UFC/g; marca "B": 2,2×10 $\mathrm{UFC/g}$; marca

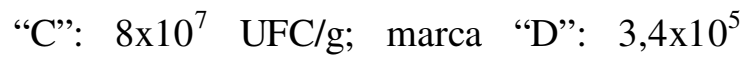

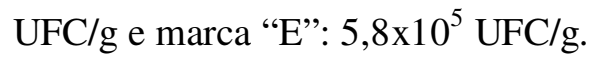

As marcas "C" e "E" foram as que apresentaram quantificações mais altas de aeróbios mesófilos e psicotrópicos indicando, provavelmente, maneiras diferentes de manipulação e armazenamento em condições higiênico-sanitárias inadequadas.

As amostras analisadas apresentaram resultado negativo para Staphylococcus coagulase positivo. No trabalho de Tavares (2002) a presença de Staphylococcus coagulase positivo foi observada em apenas uma amostra, com contagem de 5,0 x10 UFC/g. Para Staphylococcus sp as marcas "B” e "D" apresentaram ausência de contagem, no entanto a marca "A" apresentou média de 1x10UFC/g; a marca "C": 1,4x10UFC/g e a marca "E": $1,4 \times 10^{3} \mathrm{UFC} / \mathrm{g}$. A toxinose alimentar por $S$. aureus requer a ingestão acima de $10^{5}$ organismos/g de alimento e/ou de $1 \mu \mathrm{g}$ de toxina/g de alimento para se iniciarem os sintomas clínicos, incluindo náusea, vômito, espasmo abdominal e, ocasionalmente, diarréia (LE LOIR; BARON; GAUTIER, 2003; FDA, 2005b).

Na legislação vigente (BRASIL, 2001) o limite aceitável para clostrídios sulfito redutor a $46^{\circ} \mathrm{C}$ é de $5 \times 10^{2}$ a $3 \times 10^{3} / \mathrm{g}$. As amostras “B”, “D” e "E” foram ausentes para tal micro-organismo, já a marca "A" apresentou média de $1 \times 10 / g$ e a marca "C" média de $0,3 \times 10 / g$.

A legislação brasileira não estabelece limites de tolerância para o grupo dos coliformes totais em hambúrgueres. Entretanto, a presença desse micro-organismo pode indicar condições higiênico-sanitárias deficientes, colocando em risco a saúde dos consumidores desses produtos. Lundgren et al. (2009) tiveram valor médio de $1,8 \times 10^{3}$ NMP/g. Segundo Kasnowski (2004), em seu trabalho com 15 amostras de carne moída, 14 amostras apresentaram contaminação que variaram entre 0 a $3 \times 10^{5} / \mathrm{g}$.

De acordo com os resultados apresentados encontrou-se ausência de Escherichia coli nas cinco marcas analisadas. Segundo a RDC 12/2001, são considerados aceitáveis valores de coliformes a $45^{\circ} \mathrm{C}$ entre $5 \times 10^{2} / \mathrm{g}$ e $5 \times 10^{3} / \mathrm{g}$. No trabalho de Kasnowski (2004), das 223 colônias isoladas, 61 foram sorotipadas como $E$. coli patogênica; sendo as cepas do grupo EPEC mais frequentes (52 colônias), seguida por EIEC (8 colônias) e a ocorrência de apenas uma cepa de EHEC. 
Tabela 1- Resultados das análises microbiológicas da carne de hambúrguer comercializada em Alfenas-MG.

\begin{tabular}{|c|c|c|c|c|c|c|c|c|}
\hline Amostras* & $\begin{array}{c}\text { Salmonella } \\
\mathrm{sp} / 25 \mathrm{~g}\end{array}$ & $\begin{array}{c}\text { FFL } \\
(\mathrm{UFC} / \mathrm{g})\end{array}$ & $\begin{array}{c}\mathrm{AM} \\
(\mathrm{UFC} / \mathrm{g})\end{array}$ & $\begin{array}{l}\text { Coliformes } \\
\text { Totais } \\
(\mathrm{NMP} / \mathrm{g})\end{array}$ & $\begin{array}{c}\text { Staphylococcus } \\
s p \\
(\mathrm{UFC} / \mathrm{g})\end{array}$ & $\begin{array}{l}\text { Clostrídios } \\
\text { sulfito- } \\
\text { redutores } \\
\text { (UFC/g) }\end{array}$ & $\begin{array}{c}\text { Psicrotróficos } \\
\text { (UFC/g) }\end{array}$ & $\begin{array}{l}E . \\
\text { coli }\end{array}$ \\
\hline A-01 & Ausente & $1,0 \times 10$ & $2,7 \times 10^{5}$ & 3,6 & $3,0 \times 10$ & Ausente & $6,0 \times 10^{4}$ & Ausente \\
\hline $\mathrm{A}-02$ & Ausente & $1,0 \times 10$ & $1,9 \times 10^{5}$ & 3,0 & Ausente & $3,0 \times 10$ & $9,6 \times 10^{4}$ & Ausente \\
\hline A-03 & Ausente & Ausente & $2,8 \times 10^{5}$ & 3,6 & Ausente & Ausente & $6,0 \times 10^{4}$ & Ausente \\
\hline B-01 & Ausente & $1,0 \times 10$ & $1,7 \times 10^{5}$ & $<3,0$ & Ausente & Ausente & $1,1 \times 10^{4}$ & Ausente \\
\hline B-02 & Ausente & $1,0 \times 10$ & $2,0 \times 10^{5}$ & 9,2 & Ausente & Ausente & $1,9 \times 10^{4}$ & Ausente \\
\hline B-03 & Ausente & $1,0 \times 10$ & $2,6 \times 10^{5}$ & 3,6 & Ausente & Ausente & $3,7 \times 10^{4}$ & Ausente \\
\hline C-01 & Ausente & $7,0 \times 10$ & $3,2 \times 10^{5}$ & 29 & $1,3 \times 10$ & Ausente & $7,0 \times 10^{4}$ & Ausente \\
\hline $\mathrm{C}-02$ & Ausente & $2,0 \times 10$ & $4,0 \times 10^{8}$ & 9,2 & $1,0 \times 10$ & Ausente & $2,0 \times 10^{8}$ & Ausente \\
\hline C-03 & Ausente & $2,8 \times 10^{2}$ & $3,0 \times 10^{8}$ & 1.100 & $2,0 \times 10$ & $1,0 \times 10$ & $5,7 \times 10^{7}$ & Ausente \\
\hline D-01 & Ausente & $7,0 \times 10$ & $2,7 \times 10^{5}$ & 23 & Ausente & Ausente & $3,2 \times 10^{5}$ & Ausente \\
\hline D-02 & Ausente & $9,0 \times 10$ & $7,0 \times 10^{4}$ & 43 & Ausente & Ausente & $3,0 \times 10^{5}$ & Ausente \\
\hline D-03 & Ausente & $1,0 \times 10$ & $1,2 \times 10^{5}$ & 23 & Ausente & Ausente & $4,0 \times 10^{5}$ & Ausente \\
\hline E-01 & Ausente & $4,0 \times 10$ & $3,2 \times 10^{5}$ & 240 & $4,0 \times 10^{3}$ & Ausente & $3,5 \times 10^{5}$ & Ausente \\
\hline E-02 & Ausente & $2,0 \times 10$ & $1,6 \times 10^{8}$ & 93 & $3,0 \times 10^{2}$ & Ausente & $6,1 \times 10^{5}$ & Ausente \\
\hline E-03 & Ausente & Ausente & $3,8 \times 10^{5}$ & 7,4 & $1,0 \times 10$ & Ausente & $7,9 \times 10^{5}$ & Ausente \\
\hline
\end{tabular}

*A - 01 a 03 (marca “A”); B - 01 a 03 (marca “B”); C - 01 a 03 (marca “C”); D - 01 a 03 (marca “D”); E -01 a 03 (marca “E”).

\section{Conclusão}

Todas as amostras se apresentaram de acordo com a RDC $\mathrm{n}^{\mathrm{o}} 12 / 2001$, por constatarem ausência de Salmonella sp e Escherichia coli.

Verificou-se de uma forma geral baixa carga de micro-organismo, exceto para aeróbios mesófilos e psicrotróficos que tendem a aumentar a capacidade deteriorante do alimento e torná-lo impróprio para consumo por sua qualidade higiênicosanitária insatisfatória.
Portanto, as marcas analisadas podem apresentar riscos devido ao processo de deterioração que poderá ser causada pela quantidade de micro-organismos aeróbios mesófilos e psicrotróficos encontrados e também para consumo pela população, mesmo dentro do prazo de validade.

\section{Referências Bibliográficas}

ALMEIDA, A. C. Determinação dos perigos microbiológicos em carnes bovinas refrigeradas, comercializadas em Diamantina. Departamento de Nutrição Faculdades Federais Integradas de Diamantina, 2004. 
Associação Brasileira das Indústrias

Exportadoras de Carnes. Pecuária Brasileira.

Disponível em: <

http://www.abiec.com.br/3_pecuaria.asp>

Acesso em: 16 de abr. 2012.

BRASIL. Ministério da Saúde. Resolução

$R^{2} n^{\circ} 12$ de 02 de janeiro de 2001 da Agência Nacional de Vigilância Sanitária-

ANVISA. Regulamento técnico sobre padrões microbiológicos para alimentos. Diário

Oficial da União. Brasília, 10 jan. 2001.

Food and Drug Administration (FDA). Center for Food Safety and Applied Nutrition (CFSAN). Bad Bug Book. Salmonella spp. December 2005a. Disponível em: <http://www.cfsan.fda.gov/ mow/chap1.html >. Acesso em: 23 de abr. 2012.

Food and Drug Administration (FDA). Center for Food Safety and Applied Nutrition (CFSAN). Bad Bug Book. Staphylococcus aureus. December 2005b. Disponível em: <http://www.cfsan.fda.gov/ mow/chap3.html >. Acesso em: 23 de abr. 2012.

JAY, J. M. Microbiologia de Alimentos. 6. ed., Porto Alegre: Artmed, 2005.

KASNOWSKI, M. C. Listeria spp., Escherichia coli: Isolamento, identificação, estudo sorológico e antimicrobiano em corte de carne bovina (alcatra) inteira e moída. 2004. 111f. Dissertação (Mestrado em Concentração em Higiene Veterinária e Processamento Tecnológico de P.O.A) Universidade Federal Fluminense, Niterói, 2004. Disponível em: <http://www.uff.br/higiene_veterinaria/teses/ maria_kasnowski_completa_mestrado.pdf> Acesso em: 18 abr. 2012.

LE LOIR, Y.; BARON, F.; GAUTIER, M. Staphylococcus aureus and food poisoning. Genet Mol Res 2: 63-76, 2003.

LUNDGREN, P. U.; SILVA, J. A.; MACIEL, J. F.; FERNANDES, T. M. Perfil da qualidade higiênico-sanitária da carne bovina comercializada em feiras livres e mercados públicos de João Pessoa/PB-
Brasil. Alim. Nutr., Araraquara v.20, n.1, p. 113-119, jan./mar. 2009. Disponível em: $<\mathrm{http}: / /$ serv-

bib.fcfar.unesp.br/seer/index.php/alimentos/ar ticle/viewFile/953/780> Acesso em: 23 de abr. 2012 .

MARCHI, P.G.F. Estudo comparativo do estado de conservação de carne moída através de métodos microbiológicos e físico-químicos. 2006. 88f. Dissertação (Mestrado em Medicina Veterinária Preventiva) - Universidade Estadual Paulista, Jaboticabal, 2006. Disponível em: $<$ http://www.athena.biblioteca.unesp.br/exlibr is/bd/bja/33004102072P9/2006/marchi_pgf_ me_jabo.pdf> Acesso em: 18 abr. 2012.

SILVA, N. et al. Manual de Métodos de Análise Microbiológica de Alimentos. 3 ed. São Paulo: Livraria Varela, 2007.

TAVARES, T. M. Avaliação microbiológica de hambúrgueres de carne bovina comercializados em sanduicherias tipo "trailers" no centro e na periferia de Goiânia/GO. 2002. 64f. Dissertação (Mestrado em Medicina Tropical) - Instituto de Patologia Tropical e Saúde Pública, Universidade Federal de Goiás, Goiânia, 2002. Disponível em:

$<$ http://www.iptsp.ufg.br/posstrictosensu/uplo ads/files/Talissa-2002.pdf> Acesso em: 22 de fev. 2011. 